\title{
Measuring the Impact of Student Background Checks on Reducing Crime in Higher Education
}

\author{
Stephanie F. Hughes ${ }^{1}$, Teressa L. Elliott ${ }^{1} \&$ Margaret Myers ${ }^{1}$ \\ ${ }^{1}$ Haile/US Bank College of Business, Northern Kentucky University, Highland Heights, Kentucky, USA \\ Correspondence: Stephanie F. Hughes, Department of Management, Haile/US Bank College of Business, \\ Northern Kentucky University, One Nunn Drive, 328 Business Center Building, Highland Heights, KY 41099, \\ USA. Tel: 859-572-1389. E-mail: hughesst@nku.edu
}

\author{
Received: April 28, 2014 Accepted: June 23, 2014 Online Published: October 29, 2014 \\ doi:10.5539/par.v3n2p121 URL: http://dx.doi.org/10.5539/par.v3n2p121
}

\begin{abstract}
There is general agreement in the literature that student-on-student crime accounts for the overwhelming majority of crimes committed on campus in the United States (Dickerson, 2008). Background checks on students as a requirement of admission is one tool that may prove effective in reducing crime on campus. So far only one state, North Carolina, has enacted a modified version of such a requirement for admission to their public institutions of higher education. Specifically, North Carolina state schools have implemented background checks on students who first self-disclose to either criminal or disciplinary violations as part of the application process. The actual size of this opt-in group is not known, but the opportunity to assess the effectiveness of the first state-wide initiative to background check students at the point of admission is the motivation for this study. This preliminary study uses the data gathered under the reporting requirements of the Clery Act to assess the impact of student background checks on the reported level of crime in the state schools in North Carolina. The results preliminarily suggest that the implementation of a modified student background check policy, requiring prior self-disclosure to a criminal or disciplinary violation, as a requirement to run a background check, has not contributed to a reduction in the total number of criminal activities on those campuses as reported in the Clery data. Given the limited number of schools assessed, the lack of information about how many students opted in to the disclosure and the lack of a comprehensive application of the background check policy on all admitted students, much more research needs to be done in this area before a strong causal argument can be made that student background check practices do not contribute to observed reductions in campus crime as measured by the number of Clery Act reports for the universities included in this research.
\end{abstract}

Keywords: admissions, background checks, Clery Act, crime on campus, student-on-student

\section{Introduction}

For over 20 years there has been an escalating expectation in the United States that university administrators should be proactive in protecting their campuses from crime. In the 1990s, the reporting of campus crime as mandated by federal legislation, which became known as the Jeanne Clery Act, was seen as sufficient to fulfill this duty. Since 2004, four states have enacted requirements that their public institutions of higher education conduct criminal background checks on prospective employees; and since 2006, a handful of individual institutions and one state system of higher education, North Carolina, have instituted background checks as a requirement for student enrollment. This study is designed to evaluate the impact of criminal background checks of students in reducing campus crime in an effort to create safer learning environments.

\section{Background Checks and Crime Reduction}

In general, there is substantial debate around whether criminal background checks are effective at reducing the rate of criminal activity. Much of the opposition to the use of criminal background checks in employment settings has to do with the inability of ex-convicts to obtain jobs after incarceration despite having served time for their criminal behavior (Stoll \& Bushway, 2008). Additionally, given inconsistencies in the way criminal data are both collected and accessed across states and at the federal level, background checks, whether done by private entities or by the government, are argued to not consistently yield complete and accurate information on applicants' criminal histories (Milam, 2006). 
There have been few studies that considered whether or not criminal background checks were effective at actually reducing criminal activity. The lack of empirical data surrounding this question has, in large part, been due to the fact that there are few environments where the data can be effectively collected and compared across different environments. Generally speaking, most studies that attempt to assess the utility of background checks to reduce crime are done at an aggregate state or national level and typically are tied to the reduction in a specific type of crime. For example, Ruddell \& Mays (2004) found that, after controlling for many economic and social conditions, states with less stringent background checks on firearms purchases were more significantly associated with firearms homicides. Conversely, the authors contend that in states with more effective state criminal background checks, background check processes may temporarily frustrate an unauthorized person from obtaining a firearm that, in turn, may contribute to lower firearms homicide rates. Similarly, Sumner, et al., (2008) measured the extent of firearm death rates relative to the type of background check (federal, state or local-level check) performed at the time the guns used in these deaths were purchased. Their findings suggest that performing local-level criminal background checks was associated with a $27 \%$ lower firearm suicide rate and a $22 \%$ lower homicide rate in adults at least 21 years of age. The main difficulty in attempting to measure the impact of background checks on crime reduction has been the inability to quantify the impact of something that did not happen and to tie that absence to the utilization of background checks as the primary reason.

\section{Campus Crime}

\subsection{The Jeanne Clery Act}

In 1986, a college freshman, Jeanne Clery, was raped and murdered in her dorm room at Lehigh University by a fellow student. Her murder and the lack of transparency about campus crime rates in general, spurred her parents to begin a campus safety advocacy movement that eventually led to the passage of the Jeanne Clery Act in 1990 . This legislation required any college campus, that received federal student aid, to annually collect and publish campus crime statistics, so that prospective students and their parents could make educated decisions about whether a particular school was the right fit for the student (www.securityoncampus.org). Overall, while the rate of crime on U.S. college campuses from 2007-2010 has dropped a dramatic 22\% (see Table 1) this decline may reflect the broader national trend towards lower crime rates: violent crime (defined by FBI's Uniform Crime Reporting Program as "composed of four offenses: murder and non-negligent manslaughter, forcible rape, robbery, and aggravated assault") is down $15 \%$, and property crime has decreased by $11 \%$ in the same time frame (Hughes et al., 2014).

Table 1. Total number of Clery act reports 2007-2010 (on campus)

\begin{tabular}{lcccc}
\hline & $\mathbf{2 0 0 7}$ & $\mathbf{2 0 0 8}$ & $\mathbf{2 0 0 9}$ & $\mathbf{2 0 1 0}$ \\
\hline Murder and Non-Negligent Manslaughter & 45 & 16 & 18 & 15 \\
Negligent Manslaughter & 4 & 3 & 0 & 1 \\
Sex Offenses-Forcible & 2,740 & 2,676 & 2,608 & 2,936 \\
Sex Offenses-Non-forcible & 43 & 37 & 72 & 35 \\
Robbery & 1,966 & 1,967 & 1,874 & 1,819 \\
Aggravated Assault & 2,784 & 2,719 & 2,625 & 2,532 \\
Burglary & 30,435 & 29,612 & 23,937 & 22,222 \\
Motor Vehicle Theft & 4,951 & 4,371 & 4,267 & 3,624 \\
Arson & 789 & 709 & 653 & 742 \\
Totals & $\mathbf{4 3 , 7 5 7}$ & $\mathbf{4 2 , 1 1 0}$ & $\mathbf{3 6 , 0 5 4}$ & $\mathbf{3 3 , 9 2 6}$ \\
\hline
\end{tabular}

Source: 2013 U.S. Department of Education Crime Statistics Online

\subsection{Downward Trend in Crimes}

While the Clery data may indicate that there is a general downward trend of crimes occurring on college campuses, there are many campus crime experts who contend that, in fact, the Clery reports published by colleges and universities are underreporting the actual numbers of crimes that are occurring on campus. This underreporting may be due, in large part, to victims either discounting the actual impact of the crime itself or because they knew the perpetrator and felt it was a personal matter that should be resolved between the parties 
themselves (Hart, 2003; Baum \& Klaus, 2005). The fact that Clery Act reporting guidelines do not include categories for crimes such as larceny, which tend to occur at significantly higher levels on college campuses, along with threats, harassment and vandalism, may also account for the assumed underreported levels of campus crime (Fisher et. al., 2002; Carr, 2007).

\subsection{Extent of Underreporting}

The extent of this underreporting is not insignificant according to these experts. Sloan et al.'s (1997) study of college students' crime reporting practices found that approximately $75 \%$ of all campus crime was not reported to campus security staff and this included an estimated $82 \%$ of all violent crimes and approximately $78 \%$ of all theft and burglaries. Hart (2007), incorporating data from the National Crime Victimization Survey, reported that college students aged 18-24 experienced, but did not always report, an estimated 460,000 violent victimizations annually, including instances of rape, sexual assault, robbery, and aggravated assault. The patterns of non-reporting were also consistent across gender with a reported $95 \%$ of female college rape victims failing to report these assaults to police while male students experience rates of both violent (Hart 2007) and nonviolent victimization (Fisher et. al., 1998) at levels higher than female college-aged students.

Clery Act reports are categorized by arrests, criminal offenses, disciplinary violations (involving liquor violations, drug arrests and illegal weapon possessions), hate crimes and fires (or arsons). It has been suggested by some that alcohol and drugs are often directly associated with a substantial number of campus criminal offenses (Sloan, 1994; Hart \& Miethe, 2011) and data from Table 2 would seem to further suggest that there exists an issue of underreporting of campus criminal offenses when these data are compared to the Clery Act data outlined in Table 1.

Table 2. Total number of Clery act disciplinary violations 2007-2010

\begin{tabular}{lrrrr}
\hline & $\mathbf{2 0 0 7}$ & $\mathbf{2 0 0 8}$ & $\mathbf{2 0 0 9}$ & $\mathbf{2 0 1 0}$ \\
\hline Illegal Weapon Possessions & 1,986 & 1,822 & 1,576 & 1,642 \\
Drug Arrests & 31,749 & 35,711 & 39,741 & 44,616 \\
Liquor Violations & 195,528 & 193,158 & 193,428 & 194,441 \\
Total & $\mathbf{2 2 9 , 2 6 3}$ & $\mathbf{2 3 0 , 6 9 1}$ & $\mathbf{2 3 4 , 7 4 5}$ & $\mathbf{2 4 0 , 6 9 9}$ \\
\hline
\end{tabular}

Source: 2013 U.S. Department of Education Crime Statistics Online

Irrespective of which set of numbers we utilize, it is clear that, crime as reported in the Clery data for college campuses, remains stubbornly high. One possible explanation for the high overall numbers of Clery Act reports is that existing background check policies generally do not cover students, unless students happen to work in campus work-for-hire positions. In some states though, even student workers are exempt from these policies and it is left to the discretion of individual campuses and their administrators as to whether or not they will include student-workers under their background check policies. Because according to Dickerson "students are the main perpetrators of crime on campus" (p. 423), this means that some very significant percentage of Clery Act reports generated annually involve student-on-student crime, and efforts to reduce overall Clery Act reports will not work until strategies to address this aspect of campus safety are developed and implemented.

\section{Clery Data and Criminal Background Checks on College Campuses}

This study of the impact of criminal background checks on pre-matriculated students and campus crime follows the Hughes et al., (2014) methodology in their study of criminal background checks, by using "Clery" data to evaluate pre- and post-implementation of various institutional and legal mandates surrounding background checks and the overall level of crime reported at colleges and universities. These data are available from the U.S. Department of Education's Campus Crime Statistics tool mandated by the Crime Awareness and Campus Security Act of 1990, known as the Clery Act, which tabulates "on-campus" crime for all postsecondary institutions that receive Title IV funding (i.e., those that participate in federal student aid programs).

At least four states have enacted legislation since 2004 to implement background checks of the criminal backgrounds of their prospective employees, while two states have implemented background checks based on recommendations from the state's Board of Regents (Hughes et al., 2014). These policies generally cover all new hires, including, in some cases, all new student hires. Recent analysis of the volume of Clery Act reports for each school in those states with mandated background check policies suggests that these policies do not seem to be 
having a positive impact at reducing the rate of Clery Act reports per 1,000 students based on a pre-and post-background check assessment (Hughes et al., 2014). Further, when the quality of the background check being utilized is also included in the analysis, the results continue to show that there is no change in the Clery Act incident levels when comparing their pre-background check activity with their post-background check implementation. While these results appear to suggest that schools are spending a great deal of money on a process that does not seem to be having much impact on reducing criminal activity, the study results may inadvertently provide support to the recognition that the Clery data tend to reflect more student-on-student criminal activity whereas the background checks analyzed in this earlier study were applied only to new hires or transfers to new positions primarily comprised of faculty and staff positions. While student employees were sometimes covered in these policies, the general student population was not, thus setting the stage for this follow-up study that looks at Clery Act data in universities that are utilizing background checks in their admissions practices.

North Carolina is one state that has begun to try to address the issue of student criminal activity. In 2006, due to several high profile criminal cases involving students admitted to their state institutions, North Carolina implemented policies to address the possible criminal backgrounds of students entering their state institutions of higher education. This study will investigate the prevalence of criminal activity on college campuses in North Carolina's State Higher Education system by assessing the reported crime statistics in their Clery Act reports for the years preceding and the years following the passage of their 2006 criminal background check legislation.

\section{Student Background Checks and State Initiatives}

\subsection{Overview of Admissions}

According to a 2010 American Association of Collegiate Registrars and Admissions Officers (AACRAO) survey, $66 \%$ of responding institutions indicated that they collect criminal justice information in the admission process (Epstein, 2010). This information is usually gathered primarily through self-disclosure questions found on the institution's application. Of the 144 institutions that responded, only $10(6.9 \%)$ actually conducted criminal checks.

Dickerson (2008) provides a thoroughly comprehensive overview of the legal and policy considerations involved in conducting background checks as part of the admission practices of a school. In her words, "A school would not consider allowing an applicant to self-report their own SAT score without independent validation, so allowing or depending strictly on self-disclosure of criminal activity by a student seems illogical" (Dickerson, 2008 , p. 421). Schools that rely on self-disclosure as their only form of check on the potential risk posed by a student are, quite possibly, placing themselves and the students they serve at higher risk. While opponents of running background checks on students will point out the many procedural, legal and fairness issues inherent in running background checks on students who are either still juveniles under the law, have little background accumulated to actually check and who may be disqualified for a lifetime from pursuing higher education because of decisions made as a juvenile (Mann, 2007), Dickerson (2008) contends that background checks on students are "an idea whose time has come."

\subsection{Common Application}

The acceleration and the often high profile nature of student-on-student crime prompted the makers of the Common Application in 2006 to add a self-disclosure question to the application that required students and guidance counselors to disclose if students had been convicted of a crime or had committed a school violation leading to dismissal, expulsion, suspension or probation (Pappano, 2007). The Common Application is now in use at 517 institutions both here in the U.S. and internationally (Common Application, 2013). While the use of the Common Application has grown in the past several years, currently there are no federal laws either requiring or prohibiting institutions of higher education from conducting background checks on incoming students (Dickerson, 2008).

\subsection{State Initiatives}

There are increased efforts at the state level, however, to begin to address these requirements. In 2006, Virginia began debating, but subsequently never passed, a requirement that would require in-state colleges and universities to report identifying information on their admitted students to compare against the state sex-offender registry (Goldstein, 2006). Also in 2006, in response to two murders on the UNC-Wilmington campus, the UNC system adopted the "Regulation on Student Applicant Background Checks." This regulation required all UNC campuses to adopt a series of checks to be performed on all admitted students to the UNC system to include: (a) cross-referencing enrollment of admitted students at other UNC campuses and, (b) the National Student 
Clearinghouse (when a method for automated checks becomes available) and until an automated method for conducting these checks becomes available, constituent institutions may limit their checks to applicants who are neither in high school at the time of the application nor show continuous enrollment in an educational institution since graduating from high school and (c) North Carolina Department of Public Instruction ("DPI") enrollment database (when it becomes available). Until the DPI database becomes available, constituent institutions will check DPI enrollment records for all North Carolina residents who do not provide a public school transcript in situations in which a high school transcript is required for admission and (d) the UNC Suspension and Expulsion Data Base (UNC Policy Manual, 2006). The policy also provides that,

UNC constituent institutions will perform criminal background checks on applicants being considered for admission, applicants admitted, or applicants offered admission who have indicated their intent to attend, before the applicant matriculates, if the application and supporting materials contain...red flags" consisting of "materially inconsistent answers that have not been satisfactorily explained," or "one or more of the six criminal background/ discipline questions indicat[es] (a) pending criminal charges, (b) acceptance of responsibility for a crime, (c) criminal convictions, or (d) school disciplinary action," or if "one or more answers" are omitted "without an acceptable explanation," or the application has an unexplained gap or any other acceptable reason. The policies also require that, "A constituent institution that is going to conduct a criminal background check must obtain the applicant's consent, either in writing or electronically, to the criminal background check and to the use of the applicant's social security number for purposes of the check" (UNC Policy Manual, 2006).

If the background check conducted by the institution reveals a record, this record(s) needs to be compared to the information provided by the applicant to determine whether the applicant poses a "significant threat to campus safety" and should be denied entry. In general, the policy is intended to provide specific guidance for university administrators regarding when to admit or not admit students with troubling disciplinary or criminal backgrounds.

\section{Student Background Checks and Institutional Initiatives}

\subsection{Program Checks}

While efforts at mandating a broad-based state policy aimed at background checks on all admitted students have not taken hold beyond the initiatives in North Carolina, there are many instances of background checks being implemented on students who are either currently in, or seeking admission to, programs in medical, health and educational fields. The argument typically offered for conducting these checks during the admissions process for certain programs is that a background check is a requirement for obtaining licensure or certification from the various accrediting bodies overseeing these professions. For example, for those interested in medical school, the requirements are becoming more and more stringent. According to Krupa (2012), "Of the nation's 70 medical boards, 46 boards in 36 states can conduct a criminal background check as a condition of licensure. Of those, 40 boards in 31 states have access to the Federal Bureau of Investigation database, according to the Federation of State Medical Boards."

While the trend definitely seems to be headed towards more checks by medical accrediting bodies, surprisingly, some 14 states today do not require any type of background check for doctors to become licensed as medical practitioners (Krupa, 2012). In the nursing profession, as well, background check requirements are generally dictated by the individual states' licensing boards. In some cases, states require only that individuals self-disclose to any criminal history as a form of background checking and this has led to some predictably bad outcomes. Recently, in Minneapolis, a nurse, Jessica Baird, who answered "no" to the criminal self-disclosure question when she renewed her license application in 2011, had an accident that injured her and another passenger. At the time of the accident, Baird had been under investigation for stealing drugs from one of her patients at the hospital where she worked. Previously, she was convicted for disorderly conduct and DWI, neither of which she self-disclosed (Baillon, 2012). A research effort by the Texas Board of Nursing in 2006 investigated whether background checks were effective at keeping criminals out of the system. The study investigated the effectiveness of self-disclosure against the use of mandated background checks which Texas moved to after 2004 Among several of the major findings, the study showed that out of a licensing population of over 257,000 , a total of 1,508 nurses were disciplined by the Board for criminal histories both before and after the implementation of the criminal background checks (CBCs) and 227 nurses were sanctioned for failing to disclose their criminal histories as required on the licensure renewal form (Smith, 2006). In taking their cue from these state licensing boards, most accredited nursing and medical schools are now requiring their newly admitted students to undergo a background check prior to admittance to ensure they can be hired upon completion of their academic 
requirements. The University of Kansas Medical Center on its website warns prospective students that:

In recent years, more and more programs and disciplines taught at KUMC and elsewhere have been required to conduct criminal background checks prior to admitting students into their graduate programs or at least prior to matriculation. It has been determined that such background checks should be required of all students admitted to programs at KUMC. As a consequence, all domestic students, as well as any international students who have been in the United States for more than 30 days prior to admission must submit to at least a standard background check through Validity Screening Solutions. In the case of students involved in direct patient contact, additional checks of Employment Disqualified Listings maintained by various health care disciplines may be required by specific programs (Criminal Background for Students, 2012).

The University of Oklahoma's College of Nursing also requires that all undergraduate and graduate students must complete a criminal history background check (Current Students Background, 2013).

Additional efforts focused on background checking certain segments of students, such as athletes, are also underway. These efforts have been spurred by high profile criminal cases such as the murder of a Baylor basketball player and the point shaving scandal at the University of Toledo (Potrafke, 2006). As such, institutions including Baylor, the University of Oklahoma and the University of Kansas have all recently implemented background checks on some or all of their student athlete populations (Marklein, 2007).

\subsection{Campus Housing}

One additional area where student background checks appear to be taking hold more aggressively is in the area of screening for dormitory housing. While legal and practical arguments abound around the application of criminal background checks on newly admitted students, there appears to be much more unanimity on performing checks for students requesting campus-owned housing. The campus housing relationship places the university in a delicate position of balancing individual privacy rights with the legal liability they may face for failing to provide a safe campus environment. Under existing tort law, campus housing departments have a duty to the students who reside in campus housing to recognize and foresee the potential risk of injury to persons or property of allowing other students, support personnel, professionals and custodial/maintenance staff unmitigated access to students' rooms (Hight \& Raphael, 2003). By requiring background checks for those associated with campus housing, universities go a long way towards reinforcing their common law duty of reasonable care for students and for meeting expectations of employees of providing a safe workplace.

\section{Methodology}

\subsection{Model and Variables Defined}

Using the Clery data as described above, and following the methodology used in an earlier study on criminal background checks for prospective employees (Hughes et al., 2014), this analysis attempts to measure the effectiveness of student background checks at reducing the rate of criminal activity on college campuses. Clery Act statistics for all four-year public institutions were collected in North Carolina for the three years before and, at a minimum, three years after implementation of student background check requirements.

As previously mentioned, for our dependent variable, we accessed the crime statistics reported through the U.S. Department of Education's Campus Crime Statistics website. These statistics are not necessarily entirely representative of all of the actual criminal activity occurring on college campuses as they represent only reports of criminal instances, not prosecutions or convictions of the alleged crimes. Other crimes may be significantly under reported because "neither schools nor victims report all relevant criminal activity, particularly with regard to sexual assaults" (Dickerson, p. 428) or because certain types of crime (i.e. larceny, harassment, stalking, etc.) are not currently captured by current Clery Act reporting guidelines (Hart, 2007). Despite these caveats, the data are considered the best available source to compare certain kinds of criminal activity across higher education institutions.

\subsection{Data Collection}

The statistics cover the following criminal offenses: criminal homicide including murder, negligent and non-negligent manslaughter, forcible and non-forcible sex offenses, robbery, aggravated assault, burglary, motor vehicle theft, and arson. The definition and coding of these crimes is taken directly from the FBI's Uniform Crime Reporting Handbook (UCR) and ensures that each school's categorization of reported crimes follows a standardized process. We compiled and analyzed the data by individual school. One important note to highlight about the data is that the Clery Act reports lag the reporting cycle by one year. So, for example, the 2011 Clery Act report for a college will present data from 2010, 2009 and 2008 (since schools are required to report data 
from the three prior years). As such, data collected after the date of implementation include statistics on crimes that occurred before the date of implementation. We have therefore used as many years of post-implementation data as are available from the Clery Reports. The overall Clery data are reported as a "rate per 1,000 students" to control for varying levels of student populations across institutions.

Finally, given that prior researchers found differences in the likelihood of college students to report violent versus non-violent crime (Hart, 2003 and Baum \& Klaus 2005), we disaggregated the type of Clery Act by violent and non-violent categories of criminal activity. As such, the total Clery Act numbers were divided by total student population to get a "rate per 1,000 students" for both the violent and non-violent Clery incident totals, providing two more dependent variables for analysis.

The background check data were collected in two ways. First, the individual schools' admission websites were accessed to get a copy of the school's student background check policies. Additionally, the admission officers at each school were contacted to help provide context to the data collected online. The data suggested that the background check policies did not differ among the universities in the study. This is not surprising because the North Carolina statute covering this practice is quite specific and prescriptive in its language.

\section{Hypotheses}

If schools conduct background checks, it is hypothesized that there will be lower levels of Clery Act incidents overall for two reasons. First, background check practices will discover individuals with criminal backgrounds during the admissions process who may engage in criminal activity at some future point while they are attending the university. Second, by having a background check policy in place, many individuals, with criminal backgrounds, will self-select out of the process and not attempt to seek enrollment so as not to be identified as a criminal. This leads to the following hypothesis:

Hypothesis 1: Schools that utilize background checks during the admissions process will experience lower levels of Clery incidents in the years post background check implementation than they did in the years prior to the background check implementation.

Schools that had background check policies in place at a particular point in time were given a designation of " 1 " while schools that did not have a policy in place in an identified year were coded a " 0 ."

Two additional independent variables research quality of the university and whether a university fielded a football team--were included in the analysis to see if there was an effect on the total number of Clery incidents separate from the influence of background checks. The research quality of the university is expected to play a role in the number of Clery incidents on campus given that a school with more stringent entrance requirements may attract a more serious student (Volkwein et al., 1995) who is less likely to engage in criminal activities. This leads to the following hypothesis:

Hypothesis 2: Schools with higher Carnegie classifications will experience lower levels of Clery incidents than schools with lower Carnegie classifications.

The Carnegie classification for each university was coded in the following manner: Research Universities-Very High (1); Research Universities-High Research (2); Doctoral Research Universities (3); Masters Level-Large (4); Masters Level (5); Baccalaureate (6). All information was taken from the website of The University of North Carolina Directory (http://www.northcarolina.edu/directories/index.htm-) which maintains institutional data for all 17 UNC state institutions.

Finally, there are a number of studies that have analyzed male-dominated environments, such as fraternities and the military, and their connection with higher numbers of sexual assaults (Martin \& Hummer, 1989; Brubaker, 2009). In looking more specifically at athletics as a precipitator of violence, researchers seem divided as to whether athletic participation is more (Hilldebrand et. al., 2001; Moore \& Werch, 2005) or less (Hartmann \& Massoglia, 2007) associated with deviant criminal behavior (Wallgren, 2009). In an effort to address these inconsistencies, Merten (2008) took a different angle on this issue and looked at the issue of student athletes' competitiveness characteristics and the acceptance of dating violence in these types of relationships and found that the "need to win" and not sports participation or competitiveness was a greater indicator of increased acceptability of dating violence. These findings lead to the following hypothesis:

Hypothesis 3: Schools with less competitive football programs will experience lower levels of Clery incidents in the years post background check implementation than schools with more competitive football programs.

The football status of the schools was coded in the following manner: (no Football =0; Division $1=1$; Division 2 $=2$; Division 3 = 3). No Division 3 football programs were represented in the data set so this designation was 
dropped from the analysis. The data for this variable was also collected from the website of The University of North Carolina Directory (http://www.northcarolina.edu/directories/index.htm) which maintains institutional data, including football divisional status, for all $17 \mathrm{UNC}$ state institutions.

\section{Methodology}

A multi-factor, repeated-measures, partially-nested analysis of variance (ANOVA) model is utilized in this research effort because we are interested in whether there are changes in the Clery Act rates over time due to a pre-treatment, post-treatment design when accounting for the use of background checks. This is the same analysis utilized in our prior research effort that tested whether the implementation of background checks on employees helped to reduce campus crime (Hughes et. al., 2014). Repeated-measures ANOVA is considered an appropriate technique for examining change over time when incorporating a pre- and post-treatment model design and when observing that these patterns of change vary for different groups (Urdan, 2010). We utilize three different response variables in this design including (1) Clery Incident Rate per 1,000 students; (2) Violent Clery Incident Rate per 1,000 students, and Non-Violent Clery Incident Rate per 1,000 students. We also include the following primary factors: Carnegie Classification of School, Football Classification, School (which is incorporated as a random factor nested within Background Check Type), Measurement Time (Pre-test, implementation, post-test), and Year (nested within Measurement Time).

Our model contains the following terms which are labeled with letters for simplicity:

$\mathrm{A}=$ School (17 levels)

$\mathrm{B}=$ Year- 7 levels $(-3,-2,-1,0,1,2,3)$

$\mathrm{C}=$ Time (three levels....1: prior to implementation, 2: implementation, 3: post implementation)

The model also includes factors for the Football and Carnegie classifications. So $\mathrm{C}$ is the test of whether background checks alone create any changes in Clery Incident levels. We also look at whether Carnegie Classification or Football Classification creates differences in overall Clery incident levels among the schools in the analysis. Finally, we look at the interaction term between $\mathrm{C}$ and Carnegie Classification, which we label $\mathrm{C}^{*}$ Carnegie_Class and between $\mathrm{C}$ and Football Classification, which we label $\mathrm{C}^{*}$ Football. The $\mathrm{C}^{*}$ Carnegie_Class and $\mathrm{C}^{*}$ Football interaction terms allow us to compare the pre- and post- background check implementation for schools by both Carnegie and Football Classification. We did run the Carnegie and Football Classification analysis in different models and the category of Division 3 for football was not analyzed since there were no Division 3 schools in the current data set.

\section{Results}

Table 3. ANOVA for Clery overall crime

\begin{tabular}{|c|c|c|c|c|c|}
\hline \multicolumn{6}{|c|}{ Dependent Variable: Clery Overall Crime } \\
\hline Source & DF & Type III SS & Mean Square & F Value & $\operatorname{Pr}>\mathbf{F}$ \\
\hline *Carnegie & 5 & 164.535337 & 32.907067 & 1.24 & .3675 \\
\hline Error & 8.6554 & 229.107519 & 26.470025 & & \\
\hline \multicolumn{6}{|c|}{ Error: $0.8792 * \mathrm{MS}(\mathrm{A}($ Carnegie_Class $))+0.1208 * \mathrm{MS}($ Error $)$} \\
\hline
\end{tabular}

*This test assumes one or more other fixed effects are zero

\begin{tabular}{|c|c|c|c|c|c|}
\hline Source & DF & Type III SS & $\begin{array}{l}\text { Mean } \\
\text { Square }\end{array}$ & F-value & $\operatorname{Pr}>\mathbf{F}$ \\
\hline A(Carnegie_Class) & 8 & 231.535032 & 28.941879 & 3.41 & 0.0029 \\
\hline$* \mathbf{C}$ & 2 & 3.736925 & 1.868463 & 0.22 & 0.8030 \\
\hline${ }^{*} \mathbf{C} *$ Carnegie_Class & 10 & 52.608233 & 5.260823 & 0.62 & 0.7902 \\
\hline$* \mathbf{B}(\mathbf{C})$ & 5 & 50.122664 & 10.024533 & 1.18 & .3297 \\
\hline B*Carnegie_Class $(C)$ & 25 & 169.034671 & 6.761387 & 0.80 & .7286 \\
\hline Error: MS (Error) & 56 & 475.003645 & 8.482208 & & \\
\hline
\end{tabular}

*This test assumes one or more other fixed effects are zero 


\subsection{Total Clery Incidents and Background Checks}

For the total Clery Incident Rate, there is no evidence of a pre/post difference in average incident rate for schools that implemented background checks: $\mathrm{F}(2,56)=.22$; p-value $=.8030$. As such, Hypothesis 1 which suggested that there would be lower levels of Clery incidents post-background check implementation is not supported. We also ran the analysis for both the Violent Clery Incident and the Non-Violent Clery Incident rates to see if there were differences based on the type of crime since other experts have suggested that individuals on college campuses report the types of criminal activity (violent versus non-violent) differently. As with our prior findings on the Overall Clery Incident rate, when we break down the Clery Incident rate by Violent and Non-Violent Incident rates, we find little additional evidence of any pre/post difference in incident rates. Specifically, for the Violent Clery Incident rate, there is no evidence of a pre/post difference in average incident rate: $\mathrm{F}(2,56)=1.44$; $\mathrm{p}$-value $=.2463$. For the Non-violent Clery Incident rate, there is also no evidence of a pre/post difference in average incident rate: $\mathrm{F}(2,56)=.35$; $\mathrm{p}$-value $=0.7094$.

\subsection{Total Clery Incidents and Carnegie Classification}

For the total Clery Incident rate, there is also no evidence of a pre/post difference in average incident rate for specific Carnegie Classifications: $F(5,8)=1.24$; $p$-value $=0.3675$. As such, Hypothesis 2 , which suggested that schools, with more robust Carnegie Classifications, will experience lower levels of Clery incidents than those schools with lower Carnegie Classifications, is not supported. We also ran the analysis for the Violent Clery Incident rate, and there is no evidence of a pre/post difference in average incident rate by Carnegie Classification: $\mathrm{F}(5,8)=.65 ; \mathrm{p}$-value $=.6705$. For the Non-violent Clery Incident rate, there is also no evidence of a pre/post difference in average incident rate by Carnegie Classification: $\mathrm{F}(5,8)=1.26$; $\mathrm{p}$-value $=0.3596$.

\subsection{Total Clery Incidents and Football Classification}

Finally, for the total Clery Incident rate, there is no evidence of a pre/post difference in average incident rate for schools that differed in their Football Classification $\mathrm{F}(2,11)=2.79$; $\mathrm{p}$-value $=0.1014$. As such, Hypothesis 3 , which suggested that schools with less competitive Football Classifications, will experience lower levels of Clery incidents than schools with more competitive Football Classifications, is not supported. We also ran the analysis for the Violent Clery Incident rate, and there is no evidence of a pre/post difference in average incident rate by Football Classification: $\mathrm{F}(2,12)=3.84$; $\mathrm{p}$-value $=.0522$. For the Non-violent Clery Incident rate, there is also no evidence of a pre/post difference in average incident rate by Football Classification: $F(2,12)=3,23$; $p$-value $=0.0743$. The Football Classification $p$-values were border line and it is possible with a larger sample of schools we might see a "football" effect in this model.

The only significant effect was the schools themselves and this is not relevant to the analysis because we would expect to see differences between the schools themselves.

\section{Discussion}

\subsection{General Conclusion}

These results provide very preliminary evidence that the implementation of student background check policies and practices on college campuses is not working to help reduce the total number of criminal activities on those campuses. The existing study involved only fourteen (14) universities in one state (N.C.) and incorporated an incredibly limited background check policy that only authorized checks on admitted applicants who had previously self-disclosed to prior criminal or disciplinary violations. While we do not know how many individuals actually self-disclosed, we assume that there were only a handful of actual background checks being run on potential applicants which significantly limited the risk mitigating impact of this policy. Additionally, since it is impossible to argue the extent to which background checks actually prevented something from happening, we can only speculate about the actual explanations for the lack of observed reductions in total Clery Act reports post-background check implementation.

\subsection{Underreporting Criminal Pasts}

It is possible that the current process of only running background checks on those applicants who admit to past criminal actions is one reason for the lack of an observed effect. First, the number of potential students who fit these criteria is very small and their elimination from the applicant pool would have only a negligible effect on campus crime rates. Second, in a study of nursing applicants in Texas, Smith (2012) found that nursing applicants intentionally underreported their criminal past by not answering the required self-disclosure questions on their nursing license applications accurately. If students believe that their criminal past will only come to light if they admit to it, then they may have significant incentive to avoid telling the truth on their admission applications. So these students would still be admitted to the schools despite the policies intended to prevent 
their admission. Further, even if the school did run a criminal background check on an admitted student, based on perceived inconsistencies in their application, most of the potential criminal data that might exist would be protected by the juvenile status of the student and therefore, not accessible through a criminal background check, rendering the process useless for helping to identify potential applicants who might cause problems at some future point in time (Mann, 2007).

\subsection{Alcohol and Drugs}

It is also possible that the extent of crime on campus, as evidenced by the Clery reports, has more to do with the unfettered access to alcohol and recreational drugs than who the university admits. It is well documented that students will often first experiment with drugs and alcohol in college, (Hughes, 2008) likely because of the unsupervised nature of their existence, and this combination of circumstances leads to higher levels of criminal behavior. Alcohol has been identified as a key correlate in student victimization (Dowdell, 2007). So, in this scenario, students, under the influence of drugs and alcohol, would potentially engage in criminal behavior for the first time and these students would not be identified through any background check-based admission policy no matter how robust it might be.

\subsection{Increased Reporting of Crime}

There are some encouraging signs that on a national level, overall campus crime appears to be declining, and yet the lack of significant reduction in crime rates on campuses with background check policies in place is puzzling. One plausible explanation is that the high number of Clery incidents on these campuses may result from more aggressive efforts by schools to educate the campus community about the need to report and to make the process of reporting more efficient and effective which leads to higher numbers of incidents being reported. So, it is not necessarily the case that more crime is being committed; instead it may be that more crime is actually being reported and these reports are obscuring the real impact that background check policies may be having on the campus crime rates. Technology may have something to do with this phenomenon, as the availability of smart mobile phones make the process of reporting crimes more thorough and more convenient, resulting in higher levels of crime being reported.

\subsection{Insufficient Evidence}

It is possible that these results could also suggest that background checks are not actually working at all to reduce campus crime. However, given the limited number of years observed in the current data set and the narrow application of the policies themselves, there is insufficient evidence at this point to categorize the state of the success of the current efforts. Additionally, merely implementing background checks as a singular effort to reduce crime on campus is unlikely to impact the overall crime rate significantly without additional resources, such as more campus safety personnel and patrols, being devoted to keeping campuses safe. It is also the case that the majority of background check policies in university admissions or, for that matter, in university employment settings, rarely have a re-check element that requires the school to redo the background check on a regular or recurring cycle basis. As such, once the initial check has been completed, it is rare for the university to re-check individuals which can lead to individuals with records remaining a part of the campus community when their crimes would otherwise preclude their participation in campus life.

Finally, while the results of the analysis investigating the impact of both Carnegie and Football Classification on overall (including violent and non-violent) Clery incident levels were not significant, the limited number of schools and years included in the current analysis may indicate that a study with more power might very well find them to be important. Finally, we looked at the interaction between background checks and Carnegie Classification and background checks and Football Classification. The interaction terms allow us to compare the pre- and post- background check implementation for schools by both Carnegie and Football Classification. In both cases, the results were also not significant which is also not surprising given that the main effect of background checks was also not significant.

\section{Future Research}

Future research should look to provide more of a comparison of universities with student background check policies versus those without to identify whether there are substantial and differentiated patterns of Clery Act reports across these different types of institutions. Given that more and more experts within higher education are calling for implementation of background check policies in college admissions, in a few short years, there should be ample numbers of institutions that can serve as benchmarks to measure the success of these practices at reducing campus crime in the future. Additionally, there should be a more specific evaluation of individual institutional practices with respect to how they implement the policies mandated by the state. Variations in how 
these institutions choose to implement background check policies and the additional campus safety investments they make to complement their background check policies could have a substantial impact on the overall Clery Act numbers generated by individual campuses. It may be possible to identify individual school practices that are contributing to more significant reductions in overall Clery Act reports that could be replicated by other schools in the future.

Schools and employers are increasingly turning to social media to complement their efforts in evaluating prospective students and employees. While this practice has generated concern among legal experts about the potential liabilities that may result from using unverified information to evaluate a candidate for employment, there has been little discussion about the use of social media sites to evaluate student admission practices. Despite the lack of attention paid to this topic in the mainstream press, this represents a fertile area for future research as schools struggle to get a better handle on the most effective ways to evaluate the "fit" of prospective students and ensure campus safety at the same time.

\section{Acknowledgments}

A special thank you is extended to the following individuals for their assistance on the statistical analysis of the data included in this research: Joseph Nolan, Assistant Professor of Statistics and Craig Heard, The Burkardt Consulting Center, Northern Kentucky University.

\section{References}

Baillon, J. (2012). Investigators: Nursing license loophole. Fox News Twin Cities. Retrieved December 4, 2013, from http://www.myfoxtwincities.com/story/18403196/investigators-nursing-license-loophole

Baum, K., \& Klaus, P. (2005). Violent victimization of college students 1995-2002. Washington, D.C.: Bureau of Justice Statistics. Retrieved from http://www.bjs.gov/content/pub/pdf/vvcs02.pdf

Brubaker, S. J. (2009). Sexual assault prevalence, reporting and policies: Comparing college and university campuses and military service academies. Security Journal, 22(1), 56-72. http://dx.doi.org/10.1057/sj.2008.10

Carr, J. L. (2007, March/April). Campus violence white paper. Journal of American College Health, 55, 304-319. http://dx.doi.org/10.3200/JACH.55.5.304-320

Common Application. (2013). Retrieved December 19, 2013, from https://www.commonapp.org/Login\#!PublicPages/History

Criminal Background Checks for Students. (2013). Retrieved December 19, 2013, from http://www.kumc.edu/student-services/vice-chancellor-of-student-services/criminal-background-checks-for -students.html

Current Students Background Checks. (2012). Retrieved December 4, 2013, from http://nursing.ouhsc.edu/Current-Students/documents/Orientation/OKC-Orientation-Background-Checks.pd $\mathrm{f}$

Dickerson, D. (2008). Background checks in the university admissions process: An overview of legal and policy considerations. Journal of College and University Law, 34, 419-505.

Dowdall, G. W. (2007). The Role of Alcohol Abuse in College Student Victimization. In B. S. Fisher, \& J. J. Sloan (Eds.), Campus Crime: Legal, Social, and Policy Perspectives (2nd ed., pp. 167-187). Springfield, IL: Charles C. Tomas.

Epstein, J. (2010). Probing students' past. Inside Higher Education. Retrieved December 19, 2013, from http://www.insidehighered.com/news/2010/07/01/background

Fisher, B. S., Sloan, J., Cullen, F., \& Lu, C. (1998). Crime in the Ivory Tower: The level and sources of student victimization. Criminology, 36(3), 671-710. http://dx.doi.org/10.1111/j.1745-9125.1998.tb01262.x

Goldstein, B. (2006). Sex offender law causes consternation. The News Advance, June, 25.

Hart, T. C. (2003). Violent victimization of college students, 1995-2000. Washington, D.C.: Bureau of Justice Statistics. (NCJ 196143).

Hart, T. C. (2007). The violent victimization of college students: Findings from the national crime victimization survey. In B. S. Fisher, \& J. J. Sloan. (Eds.), Campus Crime: Legal, Social and Policy Perspectives (2nd ed., pp. 129-146). Springfield, IL: Charles C. Tomas.

Hart, T. C., \& Miethe, T. (2011). Violence against college students and its situational contexts: Prevalence, 
$\begin{array}{lllll}\text { patterns and policy implications. Victims and Offenders, } 6, & \text { 157-180. }\end{array}$ http://dx.doi.org/10.1080/15564886.2011.557324

Hartmann, D., \& Massoglia, M. (2007). Reassessing the relationship between high school sports participation and deviance: evidence of enduring, bifurcated effects [Electronic version]. The Sociological Quarterly, 48, 485-505. http://dx.doi.org/10.1111/j.1533-8525.2007.00086.x

Hight, D. L., \& Raphael, A. (2003). Should housing departments conduct criminal background checks? Journal of College \& University Housing, 32, 10-15.

Hildebrand, K. M., Johnson, D. J., \& Bogle, K. (2001, September). Comparison of patterns of alcohol use between high school and college athletes and non-athletes. College Student Journal, 35(3), 358-365.

Hughes, M. A. (2008). Preventing College and University Violence: A Decision-Maker's Guide to Implementing Best Practices (Unpublished doctoral dissertation). California School of Professional Psychology at Alliant International University, San Diego, CA

Hughes, S. F., Elliott, T. E., \& Myers, M. (2014) Measuring the impact of background checks on reducing crime in higher education. Public Administration Research (under review).

Mann, T. (2007). An exploratory study of the feasibility of national criminal background checks in college admissions (Unpublished doctoral dissertation). Northeastern University, Boston, MA.

Marklein, M. B. (2007). An idea whose time has come. Schools increasingly subjecting applicants to background checks", USA Today, April 18, 2007.

Merten, M. (2008). Acceptability of dating violence among late adolescents: The role of sports participation, competitive attitudes, and selected dynamics of relationship violence. Adolescence, 43(169), 31-56.

Milam, S. (2006). Student criminal background checks. NACUA Notes, 4(1), Retrieved December 23, 2013, from http://www.nacua.org/nacualert/memberversion/StudentCrimBckgndChks.asp

Moore, M. J., \& Werch, C. E. (2005). Sport and physical activity participation and substance use among adolescents. Journal of Adolescent Health, 36, 489-493. http://dx.doi.org/10.1016/j.jadohealth.2004.02.031

Pappano, L. (2007). Conduct unbecoming. New York Times. Retrieved December 31, 2012, from http://nytimes.com/2007/04/22/education/pappanobadbehavior.html

Potrafke, L. M. (2006). Checking up on student-athletes: An NCAA regulation requiring criminal background checks. Marquette Sports Law Review, 17(1), 427-450. Retrieved from http://scholarshiplaw.marquette.edu/sportslaw/vol.17/iss1/13

Ruddell, R., \& Mays, G. L. (2005). State background checks and firearms homicides. Journal of Criminal Justice, 33, 127-136. http://dx.doi.org/10.1016/j.jcrimjus.2004.12.004

Sloan, J. J. (2004). The correlates of campus crime: An analysis of reported crimes on college and university campuses. Journal of Criminal Justice, 22(1), 51-61. http://dx.doi.org/10.1016/0047-2352(94)90048-5

Sloan, J. J., Fisher, B. S., \& Cullen, F. T. (1997). Assessing the student right-to-know and campus security act of 1990: An analysis of the victim reporting practices of college and university students. Crime \& Delinquency, 43, 148-168. http://dx.doi.org/10.1177/0011128797043002002

Smith, C. A. (2006). Experience with nurses who have criminal histories. Retrieved December 19, 2012, from http://www.bon.texas.gov/disciplinaryaction/pdfs/cbc-analysis.pdf

Stoll, M. A., \& Bushway, S. D. (2008). The effect of criminal background checks on hiring ex-offenders. Criminology \& Public Policy, 7(3), 371-404. http://dx.doi.org/10.1111/j.1745-9133.2008.00516.x

Sumner, S. A., Layde, P. M., \& Guse, C. E. (2008). Firearm death rates and the association with level of firearm purchase background check. American Journal of Preventive Medicine, 35(1), 1-5. http://dx.doi.org/10.1016/j.amepre.2008.03.023

UNC Policy Manual, 700.5.1[R], adopted 10/26/06. Retrieved December 19, 2013, from http://www.northcarolina.edu/policy/index.php?pg=vs\&id=459

Volkwein, J., Szelest, B., \& Lizotte, A. (1995). The relationship of campus crime to campus and student characteristics. Research in Higher Education, 36(6), 647-670. http://dx.doi.org/10.1007/BF02208249 
Wallgren, J. (2009). An examination of criminal arrests and convictions of football atudent-athletes at Atlantic Coast Conference institutions as reported by the media (Unpublished doctoral dissertation). The University of North Carolina, Chapel Hill, NC.

\section{Copyrights}

Copyright for this article is retained by the author(s), with first publication rights granted to the journal.

This is an open-access article distributed under the terms and conditions of the Creative Commons Attribution license (http://creativecommons.org/licenses/by/3.0/). 